ORIGINAL ARTICLE

\title{
Relation between running injury and static lower limb alignment in recreational runners
}

\author{
V Lun, W H Meeuwisse, P Stergiou, D Stefanyshyn
}

Br J Sports Med 2004;38:576-580. doi: 10.1136/bjsm.2003.005488

See end of article for authors' affiliations ......................

Correspondence to: $\checkmark$ Lun, University of Calgary, Sport Medicine Center, 2500 University Dr, NW, Calgary T2N 1N4, Canada; vmylun@ ucalgary.ca

Accepted 11 August 2003
Objectives: To determine if measurements of static lower limb alignment are related to lower limb injury in recreational runners.

Methods: Static lower limb alignment was prospectively measured in 87 recreational runners. They were observed for the following six months for any running related musculoskeletal injuries of the lower limb. Injuries were defined according to six types: R1, R2, and R3 injuries caused a reduction in running mileage for one day, two to seven days, or more than seven days respectively; S1, S2, and S3 injuries caused stoppage of running for one day, two to seven days, or more than seven days respectively.

Results: At least one lower limb injury was suffered by $79 \%$ of the runners during the observation period. When the data for all runners were pooled, $95 \%$ confidence intervals calculated for the differences in the measurements of lower limb alignment between the injured and non-injured runners suggested that there were no differences. However, when only runners diagnosed with patellofemoral pain syndrome $(n=6)$ were compared with non-injured runners, differences were found in right ankle dorsiflexion (0.3 to 6.1), right knee genu varum $(-0.9$ to -0.3$)$, and left forefoot varus $(-0.5$ to -0.4$)$.

Conclusions: In recreational runners, there is no evidence that static biomechanical alignment measurements of the lower limbs are related to lower limb injury except patellofemoral pain syndrome. However, the effect of static lower limb alignment may be injury specific.
$\mathrm{R}$ unning is a popular form of recreational exercise in Canada, with an estimated $31 \%$ of Canadians running or jogging for physical fitness. ${ }^{1}$ Analysis of prospective and retrospective survey studies and cohort studies of recreational and competitive runners reveals a yearly incidence of injuries in runners of $24-85 \% .^{23}$

Risk factors for injury in any sport may be categorically divided into extrinsic or intrinsic. Static alignment measurements of leg length discrepancy $(>1 \mathrm{~cm})$, femoral neck anteversion, knee genu varum, valgum and recurvatum, excessive Q angle, patella alta, tibial torsion, increased ankle dorsiflexion, and excessive subtalar and forefoot varus have been proposed as potential intrinsic risk factors for running injury. ${ }^{4-8}$ In contrast with these observations, other studies did not find any association between running injury and measures of static lower limb alignment..$^{-11}$

Given the lack of agreement in the literature, the purpose of this study was to examine the relation between static measurements of lower limb alignment and the incidence of lower limb running injury in a prospective cohort study of recreational runners.

\section{METHODS}

The study was reviewed and approved by the University of Calgary Conjoint Health Research Ethics Board. A total of 153 recreational runners ( 82 men and 71 women) were recruited through poster advertisements placed at the University of Calgary, local running shoe stores, YMCAs, YWCAs, and other fitness facilities. The inclusion criteria were age greater than 18, running more than $20 \mathrm{~km} /$ week, and no current injury. To minimise the influence of injuries from other sports, subjects who regularly (more than four times/week) trained or participated in aerobics, dancing, basketball, volleyball, and racquet sports were excluded from the study.

Subjects who met the inclusion criteria completed a standardised questionnaire on current running mileage, past and current musculoskeletal injuries related to running, stretching and warming up habits, years of running experience, and use of orthotics. They were then given a standardised explanation of the details of the study. If the subject agreed to participate, written consent was obtained, and the following static measurements were performed: height and weight; knee genu varum and recurvatum; leg length and $\mathrm{Q}$ angle; hip internal and external range of motion (ROM); ankle dorsiflexion and plantar flexion ROM; and rear foot and forefoot valgus. The standing longitudinal arch was subjectively classified as pes planus, pes cavus, or neutral, and the degree of standing ankle pronation was subjectively classified as neutral, mild, moderate, or severe. Knee genu varum was measured as the distance in centimetres between the medial joint line of the knee when the subject stood with feet together side by side. Knee recurvatum was measured in degrees as the angle of the long axis of the femur relative to the long axis of the tibia with the subject standing with knees extended as much as possible. Leg length was measured in centimetres as the distance from the anterior superior iliac spine to the bottom of the medial mallelous with the subject lying supine. Q angle was measured in degrees as the angle formed by the line drawn from the anterior superior iliac spine to the centre of the patella relative to the line drawn from the centre of the patella to the centre of the tibial tuberosity. Hip rotation was measured in degrees with subjects sitting with feet hanging over an examination table. An inclinometer was held to the anterior aspect of the lower tibia while subjects externally and then internally maximally rotated the hips. Ankle ROM was measured in degrees with subjects lying supine. A goniometer was held against the lateral malleolus while the ankle was passively maximally dorsiflexed and then plantar flexed. These movements were measured from a starting point of the ankle being in a neutral position of $90^{\circ}$. Rear foot and forefoot valgus/varus was measured in degrees with subjects lying prone as described by Gross. ${ }^{12}$ All lower limb alignment measurements were performed by one investigator (VL). 


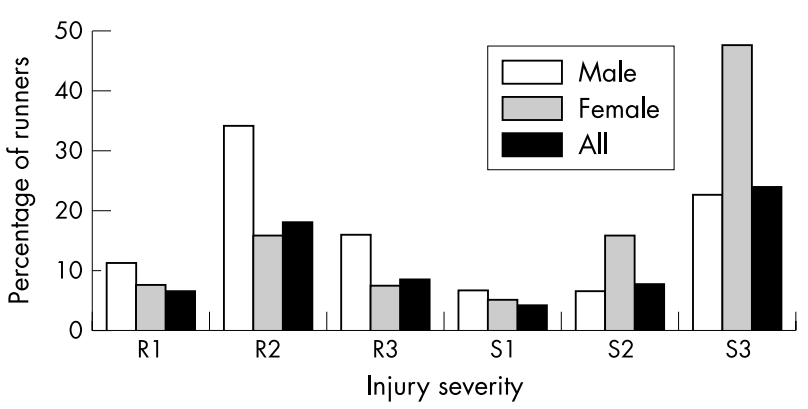

Figure 1 Injury severity summary. Type R1, R2, and R3 injuries, reduction in running mileage for one day, two to seven days, or more than seven days respectively. Type S1, S2, and S3 injuries, stoppage of running for one day, two to seven days, or more than seven days respectively.

Subjects were then observed for six months during their usual training routine (April 1998 to September 1998). All runners recorded details of each running session including shoe type, running mileage and time, indoor/outdoor, terrain (grass, gravel/dirt, asphalt, or snow), weather, temperature, and race versus training. They also documented the presence of any lower limb injury attributed to running. An injury was defined as any musculoskeletal symptom of the lower limb that required a reduction or stoppage of normal training. Running injuries were also classified as new or a recurrence of an old injury. The running logs were submitted on a monthly basis for six consecutive months.

A weekly drop-in injury clinic was available to subjects for evaluation of injuries if thought to require medical attention. These injuries were assessed by one of two sports medicine doctors at the University of Calgary Sport Medicine Centre.

Assessment of the severity of a sport related injury depends on the definition of injury. This usually reflects either the duration of the symptoms or, as in this study, training time lost due to injury. Previous studies using a time loss assessment of injury severity have used one or two weeks as the critical duration of reduced or stopped training to assess injury severity. ${ }^{213-15}$ We felt that a more precise quantification of time loss was needed, and that reduction and stoppage of training should be distinguished. Therefore the severity of injury was classified into six types: R1, R2, and R3 injuries caused a reduction in running mileage for one day, two to seven days, or more than seven days respectively; S1, S2, and S3 injuries caused stoppage of running for one day, two to seven days, or more than seven days respectively.

The relation between incidence of lower limb injury and biomechanical alignment was evaluated by calculating the 95\% confidence interval for the difference between the mean alignment measurements in the injured and non-injured runners.

\section{RESULTS}

Of the initial 153 eligible subjects, 70 completed the entire study. An additional 17 subjects participated until they dropped out because of injury. The final subject number was 87 (44 men and 43 women). The reason for dropping out by the remaining 66 subjects included: they stopped running (four); work (two); incomplete running journal (12); injury at time of recruitment (two); loss to follow up (46).

\section{Injury incidence and characteristics}

Sixty nine runners ( 35 men and 34 women) sustained at least one injury, giving an incidence of $79 \%$. This rate was the same for both sexes. The injury incidence per 1000 hours of running was $59 \%$ (both sexes combined). A total of 81

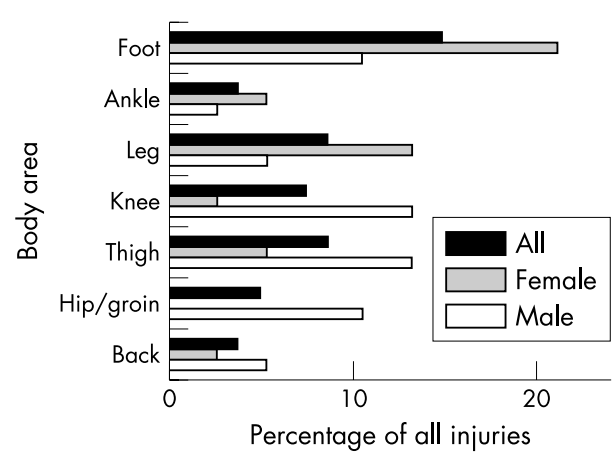

Figure 2 Location of injury.

injuries were sustained, with 11 runners experiencing two injuries and one experiencing three. Seventeen subjects had injuries that caused them to stop running completely. Only 35 of the 81 injuries were evaluated by a sport medicine doctor. The remainder were self reported. All the injuries, regardless of whether they were self reported or evaluated by a doctor, were included in the total. The pooling of these data in this manner was felt to be appropriate because the study definition of an injury was any musculoskeletal symptom that required a reduction or stoppage of a runner's usual training and not whether the injury was evaluated by a doctor. Eighteen subjects (nine men and nine women) did not sustain any injury.

Of the injuries evaluated by a doctor, the most commonly diagnosed (six) was patellofemoral pain syndrome.

According to self report, $49 \%$ of the injured runners experienced a new injury, and $29 \%$ had a recurrence of a previous injury. The onset of injury in $22 \%$ of injured runners was not known.

Injury severity (fig 1) was determined from the journals submitted by the subjects. In the male runners, R3 injuries were the most common (34\%), whereas in the female runners, S3 injuries were the most common (47\%). When data for the two sexes were combined, S3 injuries were the most common (24\%).

The location of the injury was only identified in $52 \%$ of the injured runners. The most common were foot (15\%) followed by thigh (9\%) and lower leg (9\%) (fig 2). The most common injuries seen in the male runners were knee and lower leg injuries (13\%) followed by hip/groin and foot injuries (10\%). In the female runners, the most common injuries were to the foot $(15 \%)$ followed by the thigh and lower leg (9\%).

\section{Running history and baseline characteristics}

Table 1 gives the information collected from the questionnaire and the baseline characteristics of the injured and noninjured groups and study drop outs. The average age and mean weekly running mileage were similar in the injured and non-injured groups. More runners in the injured group wore some type of in-shoe orthotic than in the non-injured group. Most runners in both groups "always" stretch (38\%), although more in the non-injured group "always" stretch compared with the injured group. Interestingly, the proportion of runners who "never" stretched was similar in the two groups. More in the non-injured group had not previously suffered any running related injury (17\%) than in the injured group $(6 \%)$. Overall, the most commonly previously injured body area was the knee ( $46 \%$ of injuries) followed by the foot $(30 \%)$ and then the shin $(22 \%)$. This pattern was similar in the injured and non-injured groups.

The proportion of injuries was similar for those with (69/ $87=0.79)$ and without $(4 / 5=0.80)$ a previous running injury. 
Table 1 Summary of data from running history questionnaire

\begin{tabular}{|c|c|c|c|c|}
\hline & $\begin{array}{l}\text { All } \\
(n=87)\end{array}$ & $\begin{array}{l}\text { Injured } \\
(n=69)\end{array}$ & $\begin{array}{l}\text { Non-injured } \\
(n=18)\end{array}$ & $\begin{array}{l}\text { Drop outs } \\
(n=64)\end{array}$ \\
\hline Age (years) & 38.0 & 38.1 & 38.3 & 36.5 \\
\hline Years running & 8.6 & 8.9 & 7.5 & 7.6 \\
\hline Runs/week & 3.8 & 3.7 & 3.8 & 3.9 \\
\hline Weekly mileage $(\mathrm{km})$ & 36.1 & 35.6 & 35.9 & 35.6 \\
\hline Run all year round & $82.0(94)$ & $65.0(94)$ & $17.0(94)$ & $56.0(87)$ \\
\hline Use orthotics & $40(46)$ & $33(48)$ & $6(33)$ & $37(58)$ \\
\hline \multicolumn{5}{|c|}{ Number of shoes used concurrently } \\
\hline One & $43(49)$ & $33(48)$ & $10(56)$ & $33(52)$ \\
\hline Two & 32 (37) & $28(41)$ & $4(22)$ & $21(33)$ \\
\hline Three or more & $12(14)$ & $8(12)$ & $4(22)$ & $8(12)$ \\
\hline \multicolumn{5}{|c|}{ Number of shoes used each year } \\
\hline One & $35(40)$ & 27 (39) & $8(44)$ & $21(33)$ \\
\hline Two & $24(28)$ & $22(31)$ & $2(11)$ & $17(27)$ \\
\hline Three or more & $24(28)$ & $14(20)$ & $8(44)$ & $18(28)$ \\
\hline \multicolumn{5}{|l|}{ Shoe selection criteria } \\
\hline Named brand & $5(6)$ & $4(6)$ & $1(6)$ & $4(6)$ \\
\hline Aesthetics & $1(1)$ & $1(1)$ & $0(0)$ & $2(3)$ \\
\hline Biomechanics & $63(72)$ & $50(72)$ & $13(72)$ & $47(73)$ \\
\hline Cost & $2(2)$ & $1(1)^{21}$ & $1(6)$ & $0(0)$ \\
\hline Recommended & $4(5)$ & $2(3)$ & $2(11)$ & $2(3)$ \\
\hline Fit & $8(9)$ & $8(12)$ & $0(0)$ & $6(9)$ \\
\hline \multicolumn{5}{|l|}{ Stretching habits } \\
\hline Always & $33(38)$ & $24(35)$ & $8(44)$ & $30(47)$ \\
\hline Often & $17(19)$ & $13(19)$ & $4(22)$ & $12(19)$ \\
\hline Sometimes & $24(28)$ & $19(27)$ & $5(28)$ & $13(20)$ \\
\hline Never & $13(15)$ & $12(17)$ & $2(11)$ & $9(14)$ \\
\hline \multicolumn{5}{|c|}{ Summary of previous injuries } \\
\hline No of injured areas & 2.1 & 2.2 & 1.7 & 1.5 \\
\hline Back & $14(16)$ & $11(16)$ & $3(17)$ & $9(14)$ \\
\hline Hip & $13(15)$ & $10(14)$ & $2(11)$ & $3(5)$ \\
\hline Thigh & $14(16)$ & $12(17)$ & $2(11)$ & $9(14)$ \\
\hline Knee & $46(53)$ & $41(59)$ & $6(33)$ & 30 (47) \\
\hline Shin & $22(25)$ & $19(27)$ & $3(17)$ & $8(12)$ \\
\hline Calf & $10(11)$ & $8(12)$ & $2(11)$ & $4(6)$ \\
\hline Ankle & $21(24)$ & $17(25)$ & $4(22)$ & $13(20)$ \\
\hline Foot & $30(34)$ & $25(36)$ & $5(28)$ & $22(34)$ \\
\hline No previous injury & $7(8)$ & $4(6)$ & $3(17)$ & $11(17)$ \\
\hline
\end{tabular}

\section{Running mileage}

The mean weekly running mileage was 30.3 and $34.2 \mathrm{~km} /$ week for the non-injured and injured groups respectively. The corresponding values were 37.6 and $38.6 \mathrm{~km} /$ week for the male runners and 23.9 and $20.4 \mathrm{~km} /$ week for the female runners. No significant differences between the injured and non-injured groups were found when 95\% confidence intervals were calculated for either the

Table 2 Summary of static measurements of lower limb alignment

\begin{tabular}{lllllll}
\hline & $\begin{array}{c}\text { Injured } \\
\text { (n=69) }\end{array}$ & SD & $\begin{array}{c}\text { Non-injured } \\
\text { (n=18) }\end{array}$ & SD & $\begin{array}{c}\text { Drop outs } \\
\text { (n=64) }\end{array}$ & SD \\
\hline Left & & & & & & \\
Hip IR & 33.85 & 7.69 & 36.56 & 7.91 & 34.6 & 8.1 \\
Hip ER & 39.43 & 9.36 & 41.00 & 9.31 & 39.9 & 8.8 \\
Knee recurv & 9.72 & 4.26 & 11.56 & 6.39 & 10.0 & 4.8 \\
Q angle & 13.67 & 5.02 & 14.67 & 4.90 & 14.4 & 9.0 \\
Ankle DF & 12.59 & 4.77 & 11.78 & 2.49 & 12.5 & 4.4 \\
Ankle PF & 49.85 & 13.12 & 52.00 & 8.93 & 52.5 & 12.5 \\
ST valgus & 1.44 & 8.42 & 0.00 & 0.00 & 4.6 & 3.2 \\
ST varus & 4.57 & 3.43 & 4.33 & 3.12 & 0.0 & 0.0 \\
FF valgus & 0.21 & 1.20 & 0.00 & 0.00 & 7.1 & 5.6 \\
FF varus & 6.62 & 3.72 & 9.67 & 4.85 & 0.1 & 0.7 \\
Right & & & & & & \\
Hip IR & 35.28 & 9.49 & 42.11 & 8.81 & 37.9 & 8.1 \\
Hip ER & 43.82 & 54.26 & 37.56 & 9.36 & 39.2 & 8.7 \\
Knee recurv & 9.44 & 4.79 & 12.56 & 6.35 & 9.9 & 4.8 \\
Q angle & 15.46 & 20.04 & 15.11 & 2.52 & 15.0 & 16.9 \\
Ankle DF & 12.34 & 4.61 & 12.00 & 3.74 & 12.0 & 4.7 \\
Ankle PF & 51.98 & 10.04 & 53.33 & 8.66 & 53.9 & 11.9 \\
ST valgus & 0.39 & 1.54 & 0.00 & 0.00 & 4.3 & 3.3 \\
ST varus & 5.03 & 3.32 & 5.33 & 2.18 & 0.0 & 0.0 \\
FF valgus & 0.15 & 1.03 & 0.00 & 0.00 & 6.5 & 5.1 \\
FF varus & 6.49 & 3.63 & 9.11 & 3.48 & 0.2 & 1.1 \\
\hline All measurements are in degrees and are means. & & & & \\
IR, Internal rotation; ER, external rotation; DF, dorsiflexion, PF, plantar flexion; ST, subtalar; FF, forefoot; recurv, \\
recurvatum.
\end{tabular}


groups as a whole and when compared on the basis of sex.

\section{Lower limb alignment and running injury}

Table 2 gives a summary of the mean static lower limb alignment measurements. None of the 95\% confidence intervals for the difference between the measurements in the injured and non-injured runners showed a significant difference except for left subtalar varus in women $(0.2$ to 4.2). However, the difference was significant when runners with patellofemoral pain syndrome were compared with noninjured runners in right ankle dorsiflexion (0.3 to 6.1), right knee genu varum $(-0.9$ to -0.3$)$, and left forefoot varus $(-0.5$ to -0.4$)$.

Table 3 shows a comparison of the subjective evaluation of the standing longitudinal arch, and table 4 a comparison of the subjective evaluation of the severity of ankle pronation. There was no obvious pattern of greater incidence of pes planus, pes cavus, or greater degree of ankle pronation in the injured group compared with the non-injured group.

\section{DISCUSSION}

Measurements of static lower limb biomechanical alignment were not found to be related to lower limb injury in recreational athletes. The findings of this study are in agreement with a number of retrospective and prospective cohort studies. Walter $e t a l^{10}$ prospectively measured femoral neck anteversion, pelvic obliquity, knee and patella alignment, and rear foot alignment in 1680 participants of two separate running races. Survey follow up after one year did not reveal a significant association of these measures with risk of injury. Montgomery et al ${ }^{9}$ prospectively measured hip extension, internal and external rotation ROM, knee flexion and extension ROM, knee varus/valgus alignment, and ankle dorsiflexion ROM, and subjectively classified the longitudinal arch of 505 male military recruits. None of the measurements were found to predispose the recruits to lower limb overuse injury. In a retrospective study, Wen et al ${ }^{11}$ correlated incidence and distribution of injury with alignment measures of arch index, heel valgus, knee tubercle-sulcus angle, knee varus, and leg length difference. The finding of only several weakly significant relations led them to conclude that measurements of static lower limb alignment were not significant related to injury. This finding was subsequently confirmed by the same authors in a prospective study using the same measures of static alignment. ${ }^{16}$ Warren and Jones ${ }^{17}$ lent further support to this when they were unable to predict runners previously or presently injured with plantar fasciitis using variables of leg length difference, ankle plantar flexion and dorsiflexion, calcaneal pronation and supination, midtarsal abduction and adduction, and arch height in a discriminate function analysis.

$\begin{aligned} & \text { Table } 3 \\
& \text { standing longitudinal arch in injured and non- } \\
& \text { subjured runners } \\
& \text { injured evaluation of static }\end{aligned}$
\begin{tabular}{llll} 
Arch type & $\begin{array}{l}\text { Injured } \\
(\mathbf{n}=69)\end{array}$ & $\begin{array}{l}\text { Non-injured } \\
(\mathbf{n}=18)\end{array}$ & $\begin{array}{l}\text { Drop outs } \\
(\mathbf{n}=63)\end{array}$ \\
\hline $\begin{array}{llll}\text { Left } \\
\text { Pes cavus }\end{array}$ & $2(3)$ & $2(11)$ & $3(5)$ \\
Neutral & $28(48)$ & $9(50)$ & $30(45)$ \\
Pes planus & $28(48)$ & $7(39)$ & $30(45)$ \\
Right & $2(3)$ & $1(6)$ & $6(9)$ \\
Pes cavus & $2(52)$ & $5(28)$ & $29(44)$ \\
Neutral & $30(44)$ \\
Pes planus & $25(43)$ & $12(67)$ & $29(44)$ \\
\hline
\end{tabular} Values in parentheses are percentages.

\begin{tabular}{|c|c|c|c|}
\hline Ankle pronation & $\begin{array}{l}\text { Injured } \\
(\mathrm{n}=69)\end{array}$ & $\begin{array}{l}\text { Non-injured } \\
(n=18)\end{array}$ & $\begin{array}{l}\text { Drop outs } \\
(\mathrm{n}=63)\end{array}$ \\
\hline \multicolumn{4}{|l|}{ Left } \\
\hline Neutral & $25(43)$ & $8(44)$ & $31(47)$ \\
\hline Mild & $29(50)$ & $9(50)$ & $28(42)$ \\
\hline Moderate & $4(7)$ & $1(6)$ & $6(9)$ \\
\hline \multicolumn{4}{|l|}{ Right } \\
\hline Neutral & $34(59)$ & $9(50)$ & $36(55)$ \\
\hline Mild & 20 (34) & 7 (39) & $24(36)$ \\
\hline Moderate & $4(7)$ & $2(11)$ & $3(5)$ \\
\hline
\end{tabular}

In this study, all the static measurements were performed by one investigator (VL). The intratester reliability was not assessed but has been reported to be good in similar studies. ${ }^{18} 19$

One potential reason why this and previous running injury studies have not found static alignment to be a running injury risk factor is the relatively low incidence of one specific injury. In this study, of the 35 injuries assessed by a sport medicine doctor, six were diagnosed as patellofemoral pain syndrome, making it the most commonly diagnosed problem. Two runners were affected in the right knee, three in the left knee, and one was affected bilaterally. Right ankle dorsiflexion, right knee genu varum, and left forefoot varus were found to be significantly different in the injured and noninjured groups. However, the small number of cases and the lack of agreement between the injured side and the significant side of alignment measurement makes it difficult to determine which of these alignment measurements (or even which combination of measurements) are clinically significant.

In contrast with our findings and those of others, various measurements of static lower limb alignment have been associated with injury in runners..$^{4-8}$ The main limitations of these studies are that they were retrospective and lacked a control group. Thus it is difficult to deduce a causative relation between alignment and injury. Of the various lower limb "misalignments", excessive subtalar pronation and pes planus or cavus longitudinal arch morphologies are probably the most commonly associated with running related injury. In this study, there was no obvious predominance of subtalar valgus or pes planus/cavus in those who were injured. This has also been reported by Wen et $a l^{11}$ and Warren and Jones. ${ }^{17}$ Furthermore, Cowan et al, ${ }^{20}$ in a prospective study, did not find a greater risk of injury in military recruits with low arch height after undergoing 12 weeks of training.

As subtalar alignment and longitudinal arch morphology change throughout the different phases of the running motion, it is likely that dynamic biomechanical assessment of these alignments may be more useful in predicting injury than static measurements. ${ }^{21}$ To address this, the subjects of this study were also involved in a parallel study in which kinematic and kinetic analysis during the stance phase of running was performed prospectively. ${ }^{22}$ The results showed that the runners who developed patellofemoral pain syndrome tended to have higher resultant abduction and external rotation moments and lower resultant extension moments at the knee than those who remained uninjured. Further studies with larger sample sizes are required to confirm this finding.

The incidence of injury over the six month observation period was $79 \%$. Compared with previous reports of yearly injury incidence in runners of $26-85 \%,{ }^{23}$ this is one of the 
highest reported when extrapolated to a yearly incidence. Hoebrig $^{23}$ has identified a number of factors that must be considered when interpreting the incidence of injury reported from a running injury study: duration of the period of observation, the running population studied, and the definition of injury. The higher incidence of injury found in this study is primarily due to the classification of injury severity into six types. Previous studies using time loss as an injury definition have used training reduction or stoppage of at least one week to define injury. Application of this definition to this study - that is, considering only type 3 and 6 injurieswould result in an injury incidence of $47 \%$. This is more similar to those previously reported.

In the female runners in our study, the foot was the most commonly injured site, followed by the leg and then the thigh. This is in contrast with that found in the male runners and in previous studies, the knee being the most commonly location of injury. ${ }^{10^{11} 13}$ The reason for this is not clear.

One limitation of the study is the high drop out rate and loss to follow up. The potential effect of this may be an underestimation of the incidence of injury, as it is not known whether the drop outs were due to injury or another reason. This limitation, along with the low number of specific injuries, also prevented the use of more sophisticated multivariate analysis techniques to assess confounding factors and interaction. Another limitation of this study is the pooling of male and female data, which may prevent identification of sex differences in laxity as a confounding factor

In conclusion, static measurements of lower limb alignment do not appear to predict injury in recreational runners. However, the effect of static lower limb alignment may be injury specific.

\footnotetext{
Authors' affiliations

V Lun, W H Meeuwisse, Sport Medicine Center, University of Calgary, Calgary, Canada

P Stergiou, D Stefanyshyn, Human Performance Laboratory, University of Calgary
}

\section{REFERENCES}

1 Government of Canada. Fitness and amateur sport. Fitness and lifestyle in Canada. Ottawa: Government of Canada, 1993.

2 Blair SN, Kohl HW, Goodyear NN. Rates and risks for running and exercise injuries: studies in three populations. Res Q Exerc Sport 1987;58:221-8.

3 Bovens AMP, Janssen GME, Vermeer HGW, et al. Occurrence of running injuries in adults following a supervised training program. Int J Sports Med 1989; 10(suppl 3):S186-90.

4 Clement DB, Taunton JE, Smart GW, et al. A survey of overuse running injuries. Phys Sportsmed 1981;9:47-58.

5 James SL, Bates BT, Osternig LR. Injuries to runners. Am J Sports Med 1978:6:40-9.

6 McNicol K, Taunton JE, Clement DB. Iliotibial tract friction syndrome in athletes. Can J Appl Sport Sci 1981;6:76-80.

7 McKenzie DC, Clement DB, Taunton JE. Running shoes, orthotics, and injuries. Sports Med 1985;2:334-47.

8 Sperryn PN, Restan L. Podiatry and the sports physician: an evaluation of orthoses. Br J Sports Med 1983;17:129-34.

9 Montgomery LC, Nelson FRT, Norton JP, et al. Orthopedic history and examination in the etiology of overuse injuries. Med Sci Sports Exerc 1989;21:237-43

10 Walter SD, Hart LE, Mcintosh, et al. The Ontario cohort study of runningrelated injuries. Arch Intern Med 1988;149:2561-4.

11 Wen DY, Puffer JC, Schmalzried TP. Lower extremity alignment and risk of overuse injuries in runners. Med Sci Sports Exerc 1997;20:1291-8.

12 Gross MT. Lower quarter screening for skeletal malalignment: suggestions for orthotics and shoewear. J Orthop Sports Phys Ther 1995;21:389-405.

13 Lysholm J, Wiklander J. Injuries in runners. Am J Sports Med 1987; 15:168-71

14 Macera CA, Russell PR, Powell KE, et al. Predicting lower-extremity injuries among habitual runners. Arch Intern Med 1989;149:2565-8.

15 Marti B, Vader JP, Minder CE, et al. On the epidemiology of running injuries. Am J Sports Med 1988; 16:285-94

16 Wen DY, Puffer JC, Schmalzried TP. Injuries in runners: a prospective study of alignment. Clin J Sport Med 1998;8:187-94.

17 Warren BL, Jones CJ. Predicting plantar fasciitis in runners. Med Sci Sports Exerc 1987; 19:71-3.

18 Astrom M, Arvidson T. Alignment and joint motion in the normal foot. J Orthop Sports Phys Ther 1995;22:216-22.

19 Loudon JK, Jenkins W, Loudon KL. The relationship between static posture and ACL injury in female athletes. J Orthop Sports Phys Ther 1996;24:91-7.

20 Cowan DN, Jones BH, Robinson JR. Foot morphologic characterstics and risk of exercise-related injury. Arch Fam Med 1993;2:723-34.

21 Nigg BM, Bahlsen AH, Denoth J, et al. Factors influencing kinetic and kinematic variables in running. In: Nigg B, eds. Biomechanics of running shoes. Champaign, IL: Human Kinetics, 1986:139-59.

22 Stefanyshyn DJ, Stergiou P, Lun VMY, et al. Knee joint moments and patellofemoral pain syndrome in runners. Part I: a case-control study. Part II: a prospective cohort study. Proceedings of the 4th Symposium on Footwear Biomechanics, 1999, 86-87.

23 Hoebrig $\mathrm{JH}$. Factors related to the incidence of running injuries. Sports Med 1992;13:408-22. 